\title{
How Does Mathematics Education Evolve in the Digital Era?
}

\author{
Dragana Martinovic and Viktor Freiman
}

In preparation for this work, we have looked into some recent curricula ideas, the international assessments (e.g., PISA), as well as the literature on the 21st century skills. For example, The New Vision for Education: Unlocking the Potential of Technology, 2015 report of the World Economic Forum lists 16 most critical 21st century skills (e.g., literacy, numeracy, ICT literacy, scientific literacy, financial literacy, cultural and civic literacy, critical thinking/problem-solving, creativity, communication, collaboration, curiosity, persistence/grit, adaptability, leadership, social and cultural awareness, and initiative), and proposes that technology is used to help people achieve these skills. How do these skills interact with ones, more specifically related to mathematics as a subject?

Multiple literacies are fundamental for the 21 st century learning, but their role in mathematics education is yet to be clarified. For this Discussion Group, the facilitators invited several experts to briefly present different international perspectives on the topic and to formulate discussion questions. Each day started with a short introduction by the facilitator, and closed with a summary of the day activities.

On Day 1, we discussed, "What are the new types of literacies that are relevant to mathematics education?"

- Financial literacy and math education (Annie Savard, McGill University, Canada). A financial concept might be introduced in the sociocultural context; learning probability and developing critical thinking in regard to gambling activities can be done through simulators of games of chance.

D. Martinovic $(\bowtie)$

University of Windsor, Windsor, Canada

e-mail: dragana@uwindsor.ca

(C) The Author(s) 2017

G. Kaiser (ed.), Proceedings of the 13th International Congress on Mathematical

Education, ICME-13 Monographs, DOI 10.1007/978-3-319-62597-3_99 
- Problem solving and math education in the digital era (Eleonora Faggiano, Università degli Studi di Bari Aldo Moro, Italia). Continuous investigation of mathematical potential of new technologies in view of mathematizable life situations and use of the synergy between the traditional and digital artefacts are crucial.

- Digital literacy and its connection to math teaching and learning: experience of the CompéTICA partnership network (ICT Competences in the Atlantic Canada) (Viktor Freiman, Université de Moncton, Canada). There is a need for development of a life-long continuum of digital competences as combination of specific digital literacy skills and 'soft' skills. Connections of such competences to math education need to be investigated.

On Day 2, we discussed, "The 21st century learning skills." We inspected models, such as those developed by Thoughtful Learning, that define the 21st century learning skills as the $4 \mathrm{C}$ 's - critical and creative thinking, communicating, and collaborating and discussed the (new) inter- and trans-disciplinary connections and the next generation of mathematics standards in view of the Vision of the Framework for K-12 Science Education.

- 'Soft' skills and math education in the digital era (Allen Leung, Hong Kong Baptist University, China, \& Anna Baccaglini-Frank, University of Pisa, Italy). Learners put into action 'soft' skills to interact with and relate to a digital environment for the purpose of acquiring mathematical knowledge and developing new digitally-based conceptions of math notions and ways of thinking.

- Creative and critical thinking in technology-rich environments (Antonella Montone, Università degli Studi di Bari Aldo Moro, Italia). Connecting mathematical and digital literacies is not only necessary, but it should also become "indispensable." The children's fairy tales which involve mathematical objects provide a natural environment in which children develop their own thinking. Technological tools like Scratch and Lego allow children to create characters, the environment, and a situation.

Open Access Except where otherwise noted, this chapter is licensed under a Creative Commons Attribution 4.0 International License. To view a copy of this license, visit http://creativecommons. org/licenses/by/4.0/.

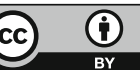

